\title{
El género, la amenaza de estereotipo y la ansiedad: evidencia psicofisiológica y cognitiva
}

\author{
Jason W. Osborne \\ Departamento del Currículo y de Instrucción, \\ Universidad del Norte de Carolina, Raleigh
}

EE.UU.

jason_osborne@ncsu.edu 


\section{Resumen}

Introducción. La hipótesis de Claude Steele sobre la amenaza de estereotipo proponía que los estereotipos negativos de grupo aumentan los niveles individuales de ansiedad, así perjudicando el rendimiento. Sin embargo, el papel de la ansiedad en la amenaza de estereotipo no ha sido explorado plenamente. Este trabajo examina la hipótesis de que una manipulación experimental de la amenaza de estereotipo influiría en medidas, en tiempo real, de la excitación fisiológica y la eficacia cognitiva en chicas y chicos que hacen exámenes de matemáticas.

Método. Los participantes eran estudiantes de una gran universidad pública de los EE.UU. Los chicos y las chicas fueron asignados aleatoriamente a condiciones o de alta amenaza de estereotipo o de baja amenaza, y después de un período de adaptación, se les presentó una tarea difícil de matemáticas, a la vez que se registraban sus medidas fisiológicas. El tiempo de procesamiento cognitivo se registró para cada item del examen.

Resultados. Los resultados indican reactancia fisiológica significativa (conductancia de la piel, temperatura de la piel, tensión arterial) como function de una manipulación de la amenaza de estereotipo. Los resultados también muestran diferencias significativas en la eficacia cognitiva como function de amenaza de estereotipo.

Conclusión. Estos hallazgos son consecuentes con el argumento que las manipulaciones de amenaza de estereotipo o incrementan o disminuyen la ansiedad específica a la situación. Los hallazgos tienen implicaciones importantes para situaciones de examen académico muy determinantes para el individuo, y para otras situaciones.

Palabras clave: género, amenaza de estereotipo, rendimiento académico, ansiedad. 